\title{
Good Intentions, Unintended Consequences, and Unrealized Benefits
}

\author{
John D. FitzGerald, MD, PhD, MBA \\ David Geffen School of Medicine, Department of Medicine, Division of Rheumatology, Rehabilitation Center, University of California at Los \\ Angeles, Los Angeles, CA, USA.
}

$\mathrm{J}$ Gen Intern Med 30(11):1581-3

DOI: $10.1007 / \mathrm{s} 11606-015-3458-4$

(C) Society of General Internal Medicine 2015

$\mathrm{T}$ he extraction of colchicine from the corm (bulb-like root) of the autumn crocus is a practice that has existed for thousands of years. The product was initially used in Egypt for its emetic properties, and about 3,000 years ago began to be used for the treatment of acute gout in Greece. The drug has been formulated into a tablet and sold to treat gout since the nineteenth century. ${ }^{1}$

The Food and Drug Administration (FDA) was established in 1938 to protect public health by assuring the safety, efficacy and security of drugs, biological products, and medical devices. However, colchicine and other drugs that were developed prior to 1938 were never evaluated or approved by the FDA. In 2006, the FDA was charged with reviewing the safety of existing non-FDA-approved drugs, and colchicine, with its many known toxicities and narrow therapeutic index, was targeted for evaluation. Intravenous colchicine was removed from the United States market in 2008. ${ }^{2}$

In response to this mandate, URL Pharma, Inc. conducted a trial to better understand the dosing of oral colchicine for use in acute gouty arthritis. ${ }^{3}$ Based on the results of this study and additional safety data, the FDA initially granted market exclusivity to URL for 3 years. With market exclusivity, URL raised the price of colchicine from $\$ 0.09$ to $\$ 5$ per tablet. In a published statement defending the FDA exclusivity decision, director Janet Woodcock, MD, noted that, "The FDA is required to implement the laws as written and has no authority to regulate drug prices... Because URL Pharma was the first to submit clinical trial data and be granted approval for oral colchicine, federal law required that the company be given marketing exclusivity for the indication of acute gout for 3 years." She also stated that, "Manufacturers could seek approval for colchicine for chronic gout; no marketing exclusivity exists for this indication." 4

To evaluate the impact of this market exclusivity, Kesselheim and colleagues analyzed colchicine use, patient costs, and the occurrence of potentially dangerous drug-drug co-prescription using a large managed care database. ${ }^{5}$ They found that after the FDA action, fewer patients used colchicine (despite safer

Published online August 4, 2015 colchicine dosing information), patient costs went up, and there was no reduction in potentially dangerous co-prescriptions. The statistical analyses are solid. There are some minor limitations commonly associated with administrative dataset analyses - for example, the indication for colchicine use in gout patients cannot be ascertained, and some gout patients may be using colchicine for prophylaxis against acute gout attack when starting uratelowering therapy rather than for management of acute gouty arthritis. However, this is unlikely to bias their analysis.

Pharmaceutical companies have a fiduciary responsibility to maximize profits for their shareholders. In a competitive market, competition lowers prices and acts in consumers' interest. (Producers are referred to as "price-takers"). Where natural or artificial monopolies exist, there is no competitive pressure to control pricing. (Producers are referred to as "price-setters"). Figure 1 illustrates colchicine pricing, quantity of tablets sold, and profits, with estimates before and after market exclusivity. (Pharmaceutical sales involve suppliers, consumers, and insurers including various discounts such as co-pay, co-insurance, patient assistance that complicate interpretation of prices and consumer behavior.) Prior to the FDA action, the competitive price of colchicine (noted as $\mathrm{P}_{\mathrm{C}}$ ) was $\$ 0.09$, thus creating the market profit for colchicine in a competitive market denoted by the dark rectangle $\left(\pi_{\mathrm{C}}\right)$ bounded below by cost of production (noted as C) and to the right by quanity produced in the competitive market (noted as Qc).

After the FDA granted URL exclusivity and monopoly power, URL set their price $\left(\mathrm{P}_{\mathrm{M}}\right)$ at $\$ 5$ per tablet and produced $\mathrm{Q}_{\mathrm{M}}$ tablets of colchicine to maximize profit $\left(\pi_{\mathrm{M}}\right)$. The Pittsburgh Post Gazette reported that URL had \$432 million in sales of colchicine (marketed as Colcrys) in 2011. ${ }^{6}$ Putting ethical considerations aside for the moment, the reduction in colchicine use, as documented by the authors, despite improved safety knowledge is a disservice to patients with acute gout attacks, familial Mediterranean fever (FMF), and other conditions treated by colchicine. (All things being equal, one would hope to see increased use of colchicine with the safer prescribing information.) Of course, patients with indications for chronic colchicine use (e.g., for pseudogout, pericarditis, and Behçet's, and prophylaxis against acute gout attack when starting urate-lowering therapy) would suffer higher costs. At a cost of $\$ 5$ per tablet on a twice-daily basis for patients on chronic therapy, the cost of a 6-month course of colchicine for a single patient would have increased from $\$ 32$ to $\$ 1800$. 


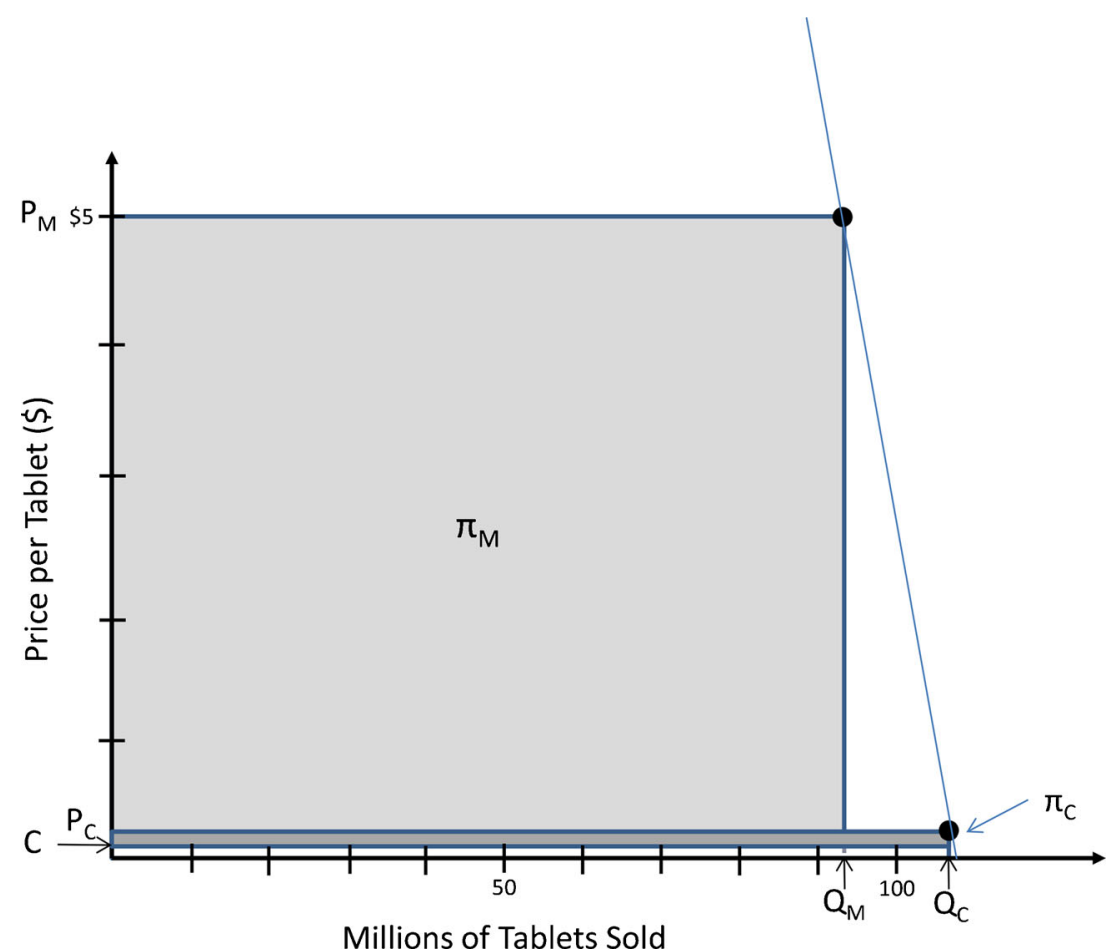

Figure. 1 Theoretical colchicine price, quantity and profit estimates. $P_{C}$ price of colchicine in a Competitive Economy, $Q_{C}$ quantity (annual) of colchicine tablets sold under competitive conditions, $\pi_{C}$ market profit (annual) from colchicine sales under competitive conditions, $C$ average cost of colchicine production, $P_{M}$ price of colchicine in a monopoly economy, $Q_{M}$ quantity (annual) of colchicine tablets sold under monopoly conditions, $\pi_{M}$ market profit (annual) from colchicine sales under monopoly conditions

The FDA behaved according to its mandates and URL behaved in the interest of its stockholders, yet outside these two groups, there was universal outrage about the observed outcomes. ${ }^{7}$ What can be done in the future to limit patient harm by such actions? Market exclusivity is an important incentive for pharmaceutical manufacturers, to compensate them for the cost of drug development. A recent Tufts Center for the Study of Drug Development report pegged the cost of bringing a new drug to market at $\$ 2.6$ billion. ${ }^{8}$ While URL's development costs are unknown, colchicine had been used for over three millennia, and the clinical trial was limited (184 patients, 1-week patient outcomes). The reward of market exclusivity seems excessive compared with the investment.

There are clear financial differences between bringing a novel drug to market and evaluating and improving the use of an existing drug, and regulators (Congress) should consider these differences. Several regulatory options exist to address monopoly power. For pharmaceutical artificial monopolies, price regulation would be the simplest and most familiar regulatory tool. Regulated monopolies often have price limits tied to production costs. As an example, utility company rates go up when resource prices (e.g., price of oil or gas) go up. Based upon the analyses by Kesselheim, unregulated pharmaceutical monopolies are unlikely to set optimal (or efficient) price-points for consumers.

Concerns about price gouging are not unique to gout. In a growing environment of more expensive medications, coupled with record pharmaceutical company profits, manufacturers need to balance societal needs with fiduciary responsibility. (Consider the new hepatitis $\mathrm{C}$ anti-viral drugs or recent oncology drugs.) Market-exclusive drug pricing needs to consider what the price ought to be rather than what the price can be. A recent opinion piece from leading cancer experts describes this well. ${ }^{9}$ In their article, they argue for "Justum Pretium, or just price, [which] refers to the 'fair value' of commodities. ... [This] advocates that, by moral necessity, price must reflect worth."

Kesselheim and colleagues have demonstrated the potential harms of monopolistic pricing. In other monopolies, it is well accepted that policymakers and regulators determine fair pricing to provide reasonable profits. To prevent a repeat of the harms observed in the colchicine experience, Congress ought to regulate pricing based on either investment costs or potential benefits. No matter the direction, the process will be complicated. While the Tufts Center for the Study of Drug Development estimated average cost of $\$ 2.6$ billion, there is likely great variability. With greater emphasis in all areas of medicine on delivering quality and benefits to patients, it might make more sense to price novel drugs or newly indicated drugs on value added to the patient. Cost-efficacy studies can shed light on potential benefits of new drugs. To set fair pricing on value added, Congress would need to mandate cost-efficacy studies as part of the FDA approval process. However, focusing solely on value added could penalize less prevalent conditions (with lower total potential population benefits). Be it either method, however (or combined cost and value strategy), some sort of price regulation (particularly for new 
indications of historic medications) is needed to prevent a repeat of the colchicine experience.

The timing of this article hopefully marks the end of the colchicine experiment. For the first time since 2010, the FDA has authorized production of a generic colchicine. Lessons learned from the colchicine experience should motivate policymakers to enact laws (as suggested above) to ensure more optimal patient outcomes, while preserving adequate incentives for the pharmaceutical industry.

Corresponding Author: John D. FitzGerald, MD, PhD, MBA; David Geffen School of Medicine, Department of Medicine, Division of Rheumatology, Rehabilitation Center University of California at Los Angeles, Room 32-59, Los Angeles, CA 90095-1670, USA (e-mail: JFitzgerald@mednet.ucla.edu).

\section{REFERENCES}

1. Nuki G, Simkin PA. A concise history of gout and hyperuricemia and their treatment. Arthritis Res Ther. 2006;8(Suppl 1):S1.
2. U.S. Food and Drug Administration. FDA Takes Action to Stop the Marketing of Unapproved Injectable Drugs Containing Colchicine Online. 2-6-2008.

3. Terkeltaub RA, Furst DE, Bennett K, Kook KA, Crockett RS, Davis MW. High versus low dosing of oral colchicine for early acute gout flare: twenty-four-hour outcome of the first multicenter, randomized, double-blind, placebo-controlled, parallel-group, dose-comparison colchicine study. Arthritis Rheum. 2010;62(4):1060-1068.

4. Woodcock J, Okada S. Incentives for drug development-the curious case of colchicine. N Engl J Med. 2010;363(15):1484-1485.

5. Kesselheim AS, Franklin JM, Kim SC, Seeger JD, Solomon DH. Reductions in use of colchicine after FDA enforcement of market exclusivity in a commercially insured population. J Gen Intern Med. 2015. doi:10. 1007/s11606-015-3285-7.

6. Sell D. URL Pharma may no longer be cash cow in Philadelphia. Online. 3-32013. Pittsburgh Post-Gazette.

7. Cohen S. The Law of Unitended Consequences Rears Its Head. The Rheumatologist 2010.

8. DiMasi JA. Tufts Center for the Study of Drug Development Briefing Cost of Developing a New Drug. http://csdd.tufts.edu/news/complete_story/cost_ study_press_event webcast. 3-2-2014.

9. Abboud C, Berman E, Cohen A, Cortes J, DeAngelo D, Deininger $\mathbf{M}$, et al. The price of drugs for chronic myeloid leukemia (CML) is a reflection of the unsustainable prices of cancer drugs: from the perspective of a large group of CML experts. Blood. 2013;121(22):4439-4442. 